\title{
Mother Tongue Policies and Mathematical Terminology in the Teaching of Mathematics
}

\author{
Mercy Kazima \\ University of Malawi \\ mkazima@chanco.unima.mw
}

\begin{abstract}
Many countries in Africa have mother tongue policies which require learners to be taught in their mother tongue for at least some of the years of primary education. This paper discusses the implementation of such policies in relation to mathematical terminology in the teaching and learning of mathematics. I present and discuss two strategies of dealing with mathematical terminology when teaching in the mother tongue: the strategy of developing mathematics registers in the local languages and the strategy of borrowing from mathematical English. I discuss the cases of Nigeria and Tanzania as examples of the former and the case of Malawi as an example of the latter. The discussion illustrates the strengths of each strategy as well as potential problems. I conclude with a discussion of implications for Malawi specifically and for any African country in general.
\end{abstract}

Mother tongue policies require that learners be taught in their mother tongue for some or all of the years of schooling. This is fairly manageable when the subject concerned is one that does not have its own highly specialised terminology. However, the picture becomes rather complicated when the subject is mathematics. The problem arises because the mathematical information comes in a register of the so called 'language of wider communication' such as English. It therefore becomes necessary to render this information into the language of the learners. In Malawi this has hitherto meant rendering it into Chichewa, among other local languages. However, it has been shown that Chichewa is currently inadequate as a vehicle for conveying scientific information in general, and mathematical information in particular because the language lacks suitable terminology for expressing scientific and mathematical concepts and ideas (Kishindo, 1987; Kishindo \& Chiotha, 1995; Kishindo \& Kazima, 2004). This finding is important because it shows that using Chichewa as the language of instruction for mathematics needs consideration of how to handle mathematical terminology to help Chichewa overcome its present limitations.

Mother tongue policies and issues of language of teaching and learning are often thought of as a dichotomy between the mother tongue and English (Setati et al., 2008). Many, including policy makers, take it to mean making a choice between teaching and learning in English or teaching and learning in the mother tongue. As Setati et al. (2008) explain,

Debates around language and learning ... create an impression that the use of the learners' home languages for teaching and learning must necessarily exclude and be in opposition to English, and the use of English must necessarily exclude the learners' home languages. (p. 3)

Setati et al. (2008) argue, however, that using home languages in the classroom does not have to be in opposition to English.

\section{The role of language in mathematics teaching and learning}

Use of English in teaching and learning mathematics involves ordinary English (as in everyday use) and mathematical English (where words and phrases have specific meanings in mathematics) (Pimm, 1987). The latter is what has been referred to as the mathematics register (Halliday, 1974). The mathematics register includes words from ordinary English but having a specialised mathematics meaning, for example, 'set', 'power', 'similar' and 'difference', and also includes words like 'polygon', 'isosceles' and 'quadrilateral' which are borrowed from other languages (Orton, 1992; Pimm, 1987). 
Studies that have investigated learners' understanding of a variety of mathematics words, have demonstrated that some learners do not understand many of the words that are commonly used in mathematics classrooms (for example, Berenson \& Vidakovic, 1996; Kazima, 2006; Otterburn \& Nicholson, 1976; Williams, 1995). In particular, learners have problems with words that have one meaning in mathematics and another in ordinary English. The word 'similar' for instance, means 'proportional' in mathematics yet in ordinary English it means 'alike'. This causes confusion because what is similar in ordinary English is not necessarily similar in mathematics, and vice versa (Orton, 1992). Pimm (1987) and Orton (1992) have given some interesting anecdotes about learners experiencing difficulties in mathematics because they do not understand the mathematical meanings of the words involved. For example, in response to the question "what is the difference between 47 and 23" one learner responded "one of the numbers is bigger than the other". When this was not accepted, he tried "one number contains a 4 and a 7 but the other number doesn't" (Orton, 1992, p. 128). Another example is that of a 13-year-old learner who counted the number of diagonals in a given figure as the number of sloping sides the figure had relative to the orientation of the page (Pimm, 1987). The learner's response to the question "if you knew the number of sides of a polygon, could you work out the number of diagonals?" was "it depends on what the shape is and which way you place it" (p. 84). The two examples show clearly that the learners did not understand the mathematical meanings of the words 'difference' and 'diagonal' and were employing the ordinary English meanings which landed them in difficulties. This is an illustration of the problems learners experience when they make errors of interpretation based on common everyday use of the words. This problem exists even for older learners as was demonstrated by Monaghan (1991). He studied A-level learners in England and observed that the word 'converges', for example, which is commonly used in calculus courses to mean 'approaches' or 'limit', was confusing for many learners. The learners could not see how sequences of numbers could converge because ordinary use of the word is strongly linked with at least two lines 'converging' and eventually meeting.

Other mathematics words, especially those borrowed from other languages, like 'isosceles' and 'quadrilateral' do not seem to occur elsewhere outside mathematics (Orton \& Frobisher, 1996). Since the words have only one meaning, learners might be able to learn the meanings without confusion with other everyday usage in ordinary English. However, some researchers have found that although some of the words can be explained in terms of their roots and origins, the words still cause problems because often learners do not remember the meanings (Berenson \& Vidakovic, 1996; Otterburn \& Nicholson, 1976; Williams, 1995).

Comprehension of mathematical word problems is another area that highlights the role of language in learning mathematics. Researchers such as Fasi (1999) and Woo-Hyung Whang (1996) explored how learners understand word problems in mathematics. A common finding was that the more competent the learners were in English the better they were at comprehending word problems. In addition, many learners with low competence in English performed better on non-verbal mathematics tasks than on mathematically equivalent word problems (Fasi, 1999), which suggests that language difficulties interfere with learners' ability to solve mathematics word problems. As Fasi concludes, the English in the word problems confuses and misleads many learners even when the mathematics involved is simple.

Other researchers (e.g. Adetula, 1990; Beecham, 2000; Jones, 1982; Berry, 1985; Bunyi, 1997) also had similar results and drew the same conclusion that language presents difficulties in learners's understanding of word problems. Furthermore, many observed that when learners do not understand the word problems they often resort to 'cue word strategy' (Adetula, 1990; Jones, 1982) that is, searching for a word that will give them a hint of which arithmetic operation to carry out. For example, it has been found that the words 'more', 'less' and 'share' prompt learners to add, subtract, and divide, respectively, regardless of what the question is asking (Adetula, 1990; Jones, 1982).

It is important to realise that language difficulties with word problems are not unique to second language speakers of English. Research has shown that even first language speakers face difficulties with word problems (De Corte \& Verschaffel, 1991; Gibbs \& Orton, 1994; Orton, 1992). However, one would expect that first language speakers have difficulties mainly with the mathematical English while second language 
speakers have difficulties in coping with the ordinary English, which they are not competent in, as well as the mathematical English.

Setati et. al.'s (2008) study which aims at helping learners with this problem of comprehension of word problems by using the learners' home languages as resources in the classroom offers versions of word problems in the learners' home languages. They conclude that this strategy improves learners' comprehension of the word problems and so makes the mathematics accessible to all the learners because they focus on the mathematics and not the language as is the case when comprehension is a problem. An interesting observation in Setati et. al.'s study is that, where one teacher translated mathematics word problems including mathematical terms into the learners' local languages, the learners found the terms harder to understand than when presented in English. Although it can be argued that it might have been the teacher's translation that was problematic, the point is that it was not easy to provide a translation that learners could understand. As Setati et al. (2008) explain the problem for learners when working with English word problems is not only with terminology but comprehension of the entire problem. This can be extended to the whole lesson to say the problem is in comprehension and communication of mathematics in the classroom, so focusing on terminology alone might not be helpful in our objectives of making mathematics accessible to learners.

The discussion above clearly illustrates that language plays an important role in the teaching and learning of mathematics. We see that mathematical terms with precise meanings in mathematics but also with everyday English meanings cause confusion for many learners. On the other hand, completely new words that do not occur elsewhere in everyday English might not be confusing for learners but they do have their own potential problems. The inference can be drawn here that mathematical terms in any language which have also everyday meanings in the everyday usage of the language would cause confusion among learners. Similarly completely new words that are not part of the language would have potential problems. What is a country to do when implementing mother tongue policy? How can a country deal with mathematical terminology when teaching in the mother tongue? I will discuss two different strategies; (a) developing a mathematics register and (b) borrowing from English. I will discuss three African countries: Tanzania and Nigeria as examples of developing a mathematics register and Malawi as an example of borrowing from English

\section{The Nigerian case}

The use of an African language as a medium of instruction has gone a long way in Nigeria. Metalanguage has been developed in the vernaculars for language, literature and teaching methods (Emenanjo, 1990; Muhammed, 1990; Bamgbose, 2004). The development of meta-languages for Nigerian languages is in keeping with the Government's National Policy on Education, which states that the medium of instruction in the first three years of primary education should be in the learner's mother tongue. Furthermore the government recognises any two of the three main languages (Hausa, Igbo and Yoruba) as core subjects for secondary school learners (Adesina, 1990). It is therefore believed that if teachers are to be produced for the use of these languages as mediums of instruction at both primary and secondary school, the teaching will extend to colleges of education and universities where teachers will be trained on how to handle the language effectively. For these reasons, the devising of mathematical terminology is considered as an important aspect of language planning. A glossary of primary mathematics has been developed in some of the languages. Table 1 shows a sample of some mathematical terms in six languages: Edo, Efik, Hausa, Igbo, Izon, and Yoruba (Bamgbose, 1986).

Table 1: Sample of mathematical terminology in six Nigerian languages

\begin{tabular}{|l|l|l|l|l|l|l|l|}
\hline & Set & \multicolumn{1}{|c|}{ Zero } & \multicolumn{1}{c|}{ Base } & \multicolumn{1}{c|}{ Sum } & \multicolumn{1}{c|}{ Factor } & \multicolumn{1}{c|}{ Point } & \multicolumn{1}{c|}{ Angle } \\
\hline Edo & Usun & Ihoi & Ezi & Esomu & Evbayagha & Ihe & Ukoko \\
\hline Efik & Ebok & Ikpikpu & Besi & Iboroedidian & Fakto & Ntoi & Itun \\
\hline Hausa & Tari & Sifili & Turke & Jumla & Ciduka & Digo & Kusurwa \\
\hline Igbo & Ikpo & Efu & Nkweongu & Mgbakota & Facto & Kpom & Mgba \\
\hline Izon & Ituu & Yefaa & Kientibi & Oseee & Diediebo & Tein lelei & Ikoki \\
\hline Yoruba & Seeto & Ofo & Ipile & Aropo & Fato & Oju & Angu \\
\hline
\end{tabular}


In addition to the terms, it is recognised that the process of teaching the various topics involves expression in the general vocabulary of description, explication and argumentation. On the whole, these already exist in the general vocabulary of the languages, but in some cases such processes may involve technical vocabulary which has also been devised. Interesting to note here is that some of the terms for example 'besi' (base in Efik), 'facto' (factor in Igbo) and 'angu' (angle in Yoruba) seem to have been borrowed from mathematical English.

According to Bamgbose (2004) teaching and learning in these languages has so far been successful. Bamgbose (2004) reports on a study that used experimental design to evaluate the effects of teaching in Yoruba. The study had two main groups of learners. An experimental group which was taught in Yoruba for all six years of primary education, and a control group which was taught in Yoruba for the first three years and followed by English the last three years. Both groups were evaluated in five subjects including mathematics. The results showed that the experimental group consistently performed better than the control group. Bamgbose (2004) concludes that teaching in the learners' language is more effective than teaching in English. By implication this claims that teaching in Yoruba and the other Nigerian languages, which involves use of the terms in table 1, has been successful.

\section{The Tanzanian case}

In Tanzania, issues of language were given priority in the process of nationalisation. Nationalisation in education meant 'Swahilisation' of the content as well as medium of instruction. The political and social vision underlying it was education for selfreliance. Swahilization meant in practical terms, creating terminology for subjects where such did not exist. Mathematical terminology has thus been developed for primary schools. This terminology has been developed on the understanding that the problem rested on ensuring that the learners understood the concepts and not the technical vocabulary, since this could be translated from English into Kiswahili (Abdulaziz, 1980). As a result a practical approach to the teaching of mathematics was followed. In teaching about the circle for example, learners would be involved in practical constructions; for example they would peg a piece of wood into the ground, tie a rope around it, and by using this rope draw a circle on the ground. In the process, concepts of centre, radius, diameter and circumference would be practically introduced and followed subsequently by the naming of the concepts (Abdulaziz, 1980). Radius for instance is called 'nusu kipenyo' which can be literally rendered into English as 'half an opening', and circle is called 'duara' literally meaning 'wheel'. Other mathematical terms developed in Kiswahili include the ones shown in Table 2.

Table 2: Sample of mathematical terminology in Kishwahili

\begin{tabular}{|l|l|l|}
\hline $\begin{array}{c}\text { Mathematical } \\
\text { English }\end{array}$ & \multicolumn{1}{|c|}{ Kiswahili } & \multicolumn{1}{c|}{$\begin{array}{c}\text { Literal } \\
\text { meaning }\end{array}$} \\
\hline Fraction & Sehemu & Portion \\
\hline Decimal & Sehenu za kumi & Portion of ten \\
\hline Percent & Sehenu za mia & Portion of hundred \\
\hline Positive & Hakika & Certainty \\
\hline Negative & Kukana & To say 'no' \\
\hline Multiply & Nyongeza & An increase \\
\hline Remainder & Mabaki & What remains \\
\hline Angle & Pembe & Angle \\
\hline Triangle & Pembe tatu & Three angles \\
\hline Quadrilateral & Pembenne & Four angles \\
\hline Rhombus & Msambamba sawa & Parallel and equal \\
\hline
\end{tabular}

The Swahili method has aimed at transferring the concept rather than mere translation. It is a faithful transfer from the source language into the target language of the concept conveying the term. Thus a literal translation of the term has been avoided because in most cases it does not convey meaning of the term. In some cases a descriptive coinage such as 'sehemu za mia' has been preferred. The Swahili examples illustrate how internal resources can be exploited to creatively develop a viable mathematical terminology. As can be seen, the vocabulary is already available in the language only that now the meanings have been extended to the realm of mathematics. The strength of the Tanzanian strategy is that it focuses on the mathematical concept of a term and not the literal translation of the term into Kiswahili. However, there is a potential problem because the literal meanings might become a source of confusion for learners. For instance the term for 'multiply' is 'nyongeza' literally meaning 'an increase'. This could be confusing for some learners since a number can be increased by adding to it. Furthermore, multiplying by zero, a negative number or a proper fraction does not increase a whole number but rather decreases it. Therefore here the problem of everyday meanings interfering with mathematical meanings, as discussed earlier, might also occur. 


\section{The Malawian case}

Malawi's mother tongue policy states that all public schools should teach in the learners' mother tongue from standard 1 to 4 - the first four years of primary education (Ministry of Education, 1996). There are at least two factors which led to this policy. Firstly, the Malawi government signed the United Nations convention of learners' rights in education which emphasised the rights of learners to be taught in their mother tongue. Secondly, the Malawi government also signed a memorandum at the African Unity which encouraged use of African languages as mediums of instruction (Chienda, 2002). Local languages in Malawi include Chichewa, Chitumbuka, Chiyawo, Chisena, Chilomwe and others. In this paper I focus on Chichewa because of its dominance as Malawi's national language.

Malawi's strategy of dealing with mathematical terminology when teaching in Chichewa was introduced by the Malawi Institute of Education. This was done through textbooks written in Chichewa which were introduced in Malawi primary schools in 1991. Before this all textbooks were in English and so mathematical terms were presented in English. Important to note here is that the Malawi Institute of Education is a government body and is the sole provider of textbooks for primary schools in Malawi. The strategy is that of borrowing from English, that is, they take terms as they are in mathematical English and spell them in Chichewa. Table 3 gives some examples.

Table 3: Sample of mathematical terminology in Chichewa

\begin{tabular}{|l|l|}
\hline Mathematical English & Chichewa \\
\hline Circle & Seko \\
\hline Decimal & Desimo \\
\hline Factor & Fakitala \\
\hline Fraction & Fulakishoni \\
\hline Multiple & Matipo \\
\hline Number & Nambala \\
\hline Percent & Pelesenti \\
\hline Quadrilateral & Kwadilatelo \\
\hline Quotient & Koshenti \\
\hline Rectangle & Rekitango \\
\hline Square & Sikweya \\
\hline Set & Seti \\
\hline Triangle & Thirayango \\
\hline
\end{tabular}

Comparing the Chichewa mathematics terms with the local language mathematical terms in the Nigerian and Tanzanian cases presented in table 1 and table 2 respectively, where the terms have meanings in the various languages, the Chichewa terms in table 3 do not have meanings in Chichewa although they are spelled in Chichewa. For example, 'triangle' in Kiswahili is 'pembe tatu' literally meaning 'three angles', and 'set' in Yoruba is 'seeto' literally meaning 'to put together'. On the other hand, the Chichewa terms 'thirayango' and 'seti' for 'triangle' and 'set' respectively, do not mean anything in Chichewa.

The strength of this borrowing strategy is that there is no confusion with Chichewa everyday use since these are not Chichewa words. Furthermore, the precision of meanings of the terms is not lost in interpretation. However, there are potential problems as has been observed in classrooms where English was the language of teaching and learning that learners do not always remember the meaning of English borrowed terms. Similarly the Malawi learners might experience the same problem with the Chichewa borrowed mathematical terms.

There is as yet no thorough research that has evaluated the effectiveness of this strategy for teaching and learning mathematics in Malawi primary schools. However, according to a small study that explored the views of teachers and learners in the effectiveness of using these terms in teaching and learning mathematics, it was found that all the teachers in the sample said it is effective to teach mathematics using the Chichewa borrowed terminology. Reasons that the teachers gave for viewing this strategy as effective were mostly that their learners could easily read and write the Chichewa borrowed mathematical terms (Kazima, forthcoming).

\section{Discussion of the three cases}

Looking across the three cases, Malawi's strategy has the advantage of easiness. First, it is easier for the developers at Malawi Institute of Education, since they only had to spell all the mathematics terms used in Malawi schools in Chichewa to present the Chichewa terminologies for schools. This saved time and made the terms available for use in schools in a short time which would not be possible where a mathematics register in the language is sought. Second, it is easier for teachers as they implement teaching in Chichewa. The teachers do not have to learn new words for Chichewa mathematical terms, since they are used to using the English words. Third, it is easier for the learners. When they proceed from standard 4 to standard 5 and onwards where the language of 
teaching is English, the learners do not learn new words for the mathematical terms that they have already encountered since the terms are the same. The learners only have to learn the English spellings and pronunciations of the terms

In contrast to the Malawi case, the Nigerian and Tanzanian cases of developing a mathematics register in their local languages took some time. Educators had consultations with many people and discussions among themselves as they developed the mathematics registers. In Tanzania for example they focused on transferring the mathematics concepts and not providing literal translations. To do this they explored their culture to find ways of presenting the mathematical concepts. This therefore demonstrated the link between mathematics in the classroom and mathematics in their culture. Consequently the strategy made the mathematical concepts relevant to the learners' everyday life. This opportunity of illustrating relevance was lost in the Malawi case. However, the challenge for Tanzania and Nigeria is to capture precise mathematical meanings in the local language terms and for teachers to avoid everyday meanings interfering with learners' understandings of the local language mathematical terms. Malawi's case avoids this confusion with everyday meanings but brings in its own problems of learners not remembering what the terms mean.

The Nigerian case is similar to Malawi's case in that the mathematical terms are one word only unlike the Tanzanian case where sometimes a description in more than one word is used, for example 'msambani sawa' for rhombus. While single word terms might be desirable for convenience, it might not be easy to get equivalent terms in the local languages which capture the mathematical meanings. However, using a description might not necessarily capture the precise meaning of the mathematical term. For example the 'msambani sawa' for rhombus literally means 'parallel and equal' which is not a precise enough description of a rhombus since a rectangle or parallelogram can also fit the description. These are some of the dilemmas that policy makers would face in making decisions about how to deal with mathematical terminology.

\section{What does this mean for Malawi?}

The strategy of borrowing from mathematical English has stirred discussion among mathematics educators and linguists in Malawi. Many have argued against the use of borrowed terminology in the Malawi textbooks and in teaching. For example Kishindo and Kazima (2000) have argued that although the terms might have the phonological structure of Chichewa, such as 'fulakishoni' (fraction) or 'sikweya' (square), they do not mean anything in Chichewa. They argue further that the underlying assumption seems to be that the learners understand the English in the first place hence the free use of 'Chichewalised' English. Kishindo and Kazima (2000) argue for the need to devise a mathematics register for Chichewa as has been done for Kiswahili in Tanzania. They suggest for example that the term 'fraction' which is called 'sehemu' in Kiswahili meaning 'portion', could be called 'gawo' in Chichewa also meaning 'portion'. This argument might seem reasonable but there is also an assumption made that if terms are in Chichewa then learners will easily understand their meanings. This assumption might not be true because the meanings that learners should understand are the mathematical meanings and not everyday meanings of the words, and sometimes these two meanings are different. Mathematical meanings are often more precise than everyday meanings. In English language it has been shown that learners find mathematical terms such as 'similar', 'difference', or 'converge' that have mathematical meanings different from everyday meanings difficult (Monaghan, 1991; Orton, 1992). Therefore it can be argued that although the Chichewa borrowed terms do not mean anything in Chichewa, learners could learn their meanings without confusion with everyday use.

Other Malawian researchers in this area also strongly recommend the development of a mathematics register in Chichewa (for example, ; Chienda, 2002; Kaphesi, 2000; Kaphesi, 2001; Rambiki, 2004). Kaphesi (2001) in particular argues that if no register is developed, then teachers might use their own Chichewa interpretations of mathematical terms which could cause confusion and mathematical misconceptions among learners. There is an assumption here as well that if a term is presented in Chichewa then it will not require further interpretations by the teacher. This is not necessarily correct because a Chichewa term could still require interpretation and explanation by the teacher. For example calling a fraction 'gawo' as suggested by Kishindo and Kazima (2000) does not mean a teacher will not have to explain its meaning, and like anything else in teaching, the explanation is subject to the teacher's interpretation and is open to confusion or misconceptions by the learners. 
It is interesting to see these arguments against the strategy of borrowing mathematical terms when according to the small survey mentioned earlier, the teachers who are the implementers seem to be happy with the strategy. The reasons the teachers gave are quite convincing especially from the point of view of the teacher whose main concern is for the child to be able to learn. The teachers all said that their learners are able to read the Chichewa borrowed terms. This shows us that, for the teachers, this ability to read the terms is important for their teaching and hence a step towards effectiveness. Indeed being able to read the terms makes it possible for the child to engage with the textbook. Whether they understand what they read is a different matter but at least they can read the terms and the teacher can take it from there.

In Setati et al.'s (2008) study, it is intriguing that in some cases learners found the local language mathematical terms (as translated by their teacher) difficult to understand. Indeed mathematical terms have precise meanings which are not easy to capture in one word in many African languages; often one needs a whole sentence to elaborate the precise meaning of a term. This seems to suggest that we should not try to present everything in the local languages; some mathematical terms might be best presented in their English form. This raises the question of whether it is worthwhile to engage in the huge task of trying to devise mathematics registers in Chichewa and other local languages that include all the mathematical terms used in schools, as is being suggested by many interested parties in Malawi. It is important to remember that it is not the name of the term that is important but the concept behind the term. For example, it is not the name 'fulakishoni' or 'gawo' that is important for learners to know but the concept of fraction.

What might be a way forward for Malawi is to evaluate the strategy to establish its level of effectiveness. Until there is evidence of lack of effectiveness in teaching using the borrowed terminology, it would not be wise to consider alternatives. If and when there is a need to consider developing a register for Malawi, again careful examination of the proposed strategy will need to be done other than copying what other countries such as Tanzania or Nigeria have done because what works for the other countries might not necessarily work for Malawi.

\section{Conclusion}

This paper has discussed issues of mathematical terminology in the context of implementing mother tongue policies. I have discussed borrowing from English and developing mathematics registers in the local languages as two strategies for handling mathematical terminology when teaching in the mother tongue. I have presented the case of Malawi as an African example of borrowing strategy and have presented the cases of Nigeria and Tanzania as African examples of developing mathematics registers in the local languages.

The discussion has illustrated the dilemmas that decision makers might face as they suggest ways of handling mathematical terminology when teaching in the local languages. Each of the strategies discussed has strengths as well as potential problems. It is therefore advisable that whatever strategy a country decides to use for its mathematical terminology, the teachers and other implementers of the strategy be aware of the strengths and potential problems so that efforts can be made to exploit the strengths and minimise the potential problems.

\section{References}

Abdulaziz, M. H. (1980). The ecology of Tanzanian national language policy. In E. Polome \& C. Hill (Eds.) Language in Tanzania. Oxford University Press.

Adesina, S. (1990). Foreword. In M. Muhamed (Ed.) Hausa Metalanguage. Volume 1. Ibadan: Ibadan University Press.

Adetula, L. (1990). Language factor: does it affect children's performance on word problems? Educational Studies in Mathematics, 21, 351-364.

Bamgbose, A. (1986, December). Guide to the selection and harmonization of educational terminology in Africa. Paper presented at the UNESCO workshop on harmonization of terminology in African languages. University of Malawi, Zomba.

Bamgbose, A. (2004). Sauce for the goose, sauce for the gander: Why an African child should be taught in an African language. In J. Pfaffe (Ed.), Making Multilingual Education a Reality for All (pp. 18-36). Zomba: Centre for Languages Studies and German Technical Cooperation (GTZ).

Beecham A. D. (2000). An exploration of the effects of cultural background, gender and age on children's attitudes and responses to arithmetical challenges and mathematical learning. Unpublished doctoral dissertation, University of Leeds. 
Berenson, S. B., \& Vidakovic, D. (1996). Children's word meanings and the development of division concepts. In L. Puig and A. Gutierrez (Eds.), Proceedings of the $20^{\text {th }}$ conference of the International Group for the Psychology of Mathematics Education, 2, 75-80. Valencia, Spain: University of Valencia.

Berry, J. W. (1985). Learning mathematics in a second language: Some cross cultural issues. For the Learning of Mathematics, 5(2), 18-23.

Bunyi, G. (1997). Multilingualism and discourse in primary school mathematics in Kenya. Language Culture and Curriculum, 10(1), 52-65.

Chienda, J. (2002). Dialects for instruction: Some insights. In Malawi Primary Curriculum Review. Ministry of Education, Science and Technology paper.

De Corte, E., \& Verschaffel, L. (1991). Some factors influencing the solution of addition and subtraction word problems. In K. Durkin \& B. Shire (Eds.), Language in mathematics education: Research and practice (pp. 117-130). Milton Keynes: Open University Press.

Emenanjo, E. (1990). Igbo Metalanguage. Volume 1. Ibadan: Ibadan University Press.

Fasi, U. (1999). Bilingualism and learning mathematics in English as a second language in Tonga. Unpublished doctoral dissertation, Reading University.

Gibbs, W., \& Orton, J. (1994). Language and mathematics. In A. Orton, \& G. Wain (Eds.), Issues in Teaching Mathematics (pp. 95-116). London: Cassell.

Halliday, M. (1974). Some aspects of sociolinguistics. In UNESCO, Interactions between Linguistics and Mathematical Education. Paris: UNESCO.

Jones, P. L. (1982). Learning mathematics in a second language: A problem with more and less. Educational Studies in Mathematics, 13, 267-87.

Kaphesi, E. (2000). English versus Chichewa in mathematics teaching. A case of teachers in selected primary schools in Zomba. In J. Pfaffe (Ed.), Local languages in education, science and technology (pp. 86-105). Zomba: Centre for language studies and German Technical Cooperation (GTZ).

Kaphesi, (2001). The use of language in mathematics teaching in primary schools in Malawi. Unpublished doctoral dissertation, University of Nottingham.

Kazima, M. (2006). Malawian students' meanings for probability vocabulary. Educational Studies in Mathematics, 64(2), 169-189.

Kazima, M. (forthcoming). Effectiveness of using Chichewa borrowed terminology in teaching and learning mathematics in Malawi primary schools.
Kishindo, P. J. (1987). The state of scientific terminology in Chichewa. Proceedings of international symposium on professional terminology in African languages: Theory and practice. Logos, 7(2), 103-113.

Kishindo, P. J., \& Chiotha S. S. (1995, February). Communicating Scientific information to peasant farmers. How effective is it? Paper presented at the Second Crop Science Conference for Eastern and Southern Africa, University of Malawi, Blantyre.

Kishindo, P. J., \& Kazima, M. (2004). Use of African languages in teaching mathematics. In J. F. Pfaffe (Ed.), Local languages in education, science and technology (pp. 106-119). Zomba: Centre for Languages Studies and German Technical Cooperation (GTZ).

Ministry of Education (1996). Use of mother tongue as a medium of instruction in standards 1, 2, 3 and 4: Circular letter reference number in/2/14, 28 March 1996, Lilongwe, Malawi.

Monaghan, J. (1991). Problems with the language of limits. For the Learning of Mathematics, 11(2), 20-24.

Muhammed, D. (1990). Hausa metalanguage. Volume 1. Ibadan: Ibadan University Press.

Orton, A. (1992). Learning Mathematics. London: Cassell.

Orton, A., \& Frobisher, L. (1996). Insights into Teaching Mathematics. London: Cassell.

Otterburn, M. K., \& Nicholson, A. R. (1976). The language of (CSE) mathematics. Mathematics in School, 5(5), 18-20.

Pimm, D. (1987). Speaking mathematically: Communication in mathematics classrooms. London: Routledge \& Kegan Paul.

Rambiki, M. (2004). Effectiveness of using Chichewa borrowed terminology in the teaching of mathematics in standards 1-4: A case study of selected primary schools in Chiradzulu district. Unpublished B Ed thesis, University of Malawi.

Setati, M., Molefe, T., Duma, B., Nkambule, T., Mpalami, N., \& Langa, M. (2008, April). Using language as a transparent resource in the teaching and learning of mathematics in a grade 11 multilingual classroom. Paper presented during the third annual symposium on teaching and learning in multilingual classrooms. University of the Witwatersrand, Johannesburg.

Williams, B. G. (1995). Language in the context of mathematical education: Some issues in learning and teaching mathematics in a second (or weakly known) language. Unpublished master's thesis, University of Leeds.

Woo-Hyung Whang (1996). The influence of English-Korean bilingualism in solving mathematics word problems. Educational Studies in Mathematics, 30(3), 289-312. 